\title{
Determining Optimum Rotary Blade Design for Wind-Powered Water-Pumping Systems for Local Selected Sites
}

\author{
Abdulbasit Mohammed ${ }^{1}$ - Hirpa G. Lemu ${ }^{2,}{ }^{*}$ - Belete Sirahbizu1 \\ ${ }^{1}$ Addis Ababa Science and Technology University, Ethiopia \\ 2 University of Stavanger, Norway
}

The design of a windmill rotor is critical for harnessing wind energy. In this work, a study is conducted to optimize the design and performance of a rotor blade that is suitable for low wind conditions. The windmills' rotor blades are aerodynamically designed based on the SG6043 airfoil and wind speed data at local selected sites. The aerodynamic profile of the rotor blade that can provide a maximum power coefficient, which is the relation between real rotor performance and the available wind energy on a given reference area, was calculated. Different parameters, such as blade shapes, chord distributions, tip speed ratio, geometries set angles, etc., were used to optimize the blade design with the objective of extracting maximum wind power for a water pumping system. Windmill rotor of $10.74 \mathrm{~m}, 7.34 \mathrm{~m}$, and $6.34 \mathrm{~m}$ diameter with three blades were obtained for the selected sites at Abomsa, Metehara, and Ziway in south-east Ethiopia. During the rotary blades performance optimization, blade element momentum (BEM) theory and solving iteration by MATLAB ${ }^{\circledR}$ coding were used.

Keywords: boundary element method, rotary sizing, wind power, hydraulic power, power coefficient, water pumping system

\begin{abstract}
Highlights
- Optimum rotary blade for wind power at low wind speed has been designed based on SG603 airfoil and analysed for three selected local sites.

- The blade design is optimized with the objective of extracting maximum wind power for each selected site for a water-pumping system.

- The relation between real rotor performance and the available wind energy on the selected given reference areas is calculated to find the optimum aerodynamic profile of the blades.

- Blade element momentum theory has been used and iterated in MATLAB to identify the parameters for the performance optimization.
\end{abstract}

\section{INTRODUCTION}

Currently, significant global progress to benefit from the need for renewable energy by converting the energy of the wind to a mechanical form by designing and constructing diverse forms of windmills exists [1]. The main interest in wind energy is that the conversion process does not release carbon emissions to the environment, and it leads to less consumption of resources. In order to mitigate the side effects of fossil fuels, the use of renewable energy sources has become extremely important. In this respect, wind energy is considered one of the most promising renewable energy sources, which forces of nature can continuously generate, and the rotor blade design is decisive in optimally harvesting wind energy.

Studies on wind turbine rotor blade design have been continuously conducted based on the performance of aerodynamic analysis. Supreeth et al. [2] used a heuristic approach to study rotary blade design for a fixed pitch and small-scale horizontal axis wind turbine. The sectional chord and twist angle distribution for the idealized, optimized, and linearized blades were analytically determined. Prasad and Virupaxi [3] designed the rotary blade of windmills for irrigational purposes in Bagur of Hosadurga district (Karnataka, India). Various parameters were optimized to achieve maximum power coefficient. Lopez-Lopez et al. [4] studied the effect of the blade slenderness and the wind speed on the dynamics and instability of wind turbine blade under large deflection. They used a simple cantilever beam model and employed a Galerkin approach validated with experimental results. Lee and Shin [5] also improved an optimization framework for blade aerodynamic design under realistic conditions.

The design parameters, such as angle of twist, chord distribution, maximum chord and the objective function relation, were obtained. Shubham et al. [6] designed and optimized the micro wind turbine blades at a rated wind speed of $8.4 \mathrm{~m} / \mathrm{s}$ using QBlade, with which the SG6043 airfoil was selected. and simulation was done on a $1.2 \mathrm{~m}$ long blade. Chan [7] reported the design of a $1.2 \mathrm{~kW}$ wind turbine blade for rural application for Mandalay Hill of Mandalay City (Myanmar) at a rated wind velocity of $7 \mathrm{~m} / \mathrm{s}$. The blade airfoil, angle of pitches and distribution of sectional chord along the blade span were determined. Deepak et al. [8] designed and optimized the blade of a small wind turbine by considering various factors, 
such as tip loss, hub loss, drag coefficient, and wake. By using blade element momentum (BEM) methods, power performance was simulated. Muhsen et al. [9] optimized the rotor blade parameters that affect blade design for small turbines with low performance due to low Reynolds number. In the optimization processes, the performance of the final designed blade performance was investigated by employing the blade element momentum theory. Norona and Krishna [10] designed a $300 \mathrm{~W}$ micro-horizontal axis wind turbine using BEM theory on SG6040 and SG6041 airfoils. The BEM procedure was codified in MATLAB software, and a $3 \mathrm{~m}$ diameter wind turbine was analysed with QBlade. In general, the literature study indicates that the efficient conversion of the wind energy directly to a mechanical form requires closer study of the local wind data and designing rotor blades that are tailormade for the wind condition.

This study focused on designing optimum rotary blades for a wind-powered water-pumping system for local selected sites at Abomsa, Metehara and Ziway (Ethiopia). This design of the blades is based on the design of an aerodynamic type of SG6043 airfoil reported by Giguere and Selig [11] and Osei et al. [12] and analysis of collected wind speed data of the sites [13] from the National Meteorological Agency (NMA). The blade parameters, including chord distribution length, angle of twist, tip speed ratio, power coefficient of the blade, and attack angle, were determined. These blades' parameters were optimized to attain maximum power coefficients by using BEM theory procedures, and different iterations were solved by MATLAB coding.

\section{DESIGN METHODS AND PROCEDURES}

The general procedures followed to design the rotor blades of the windmills for water pumping application are summarized in Fig. 1.

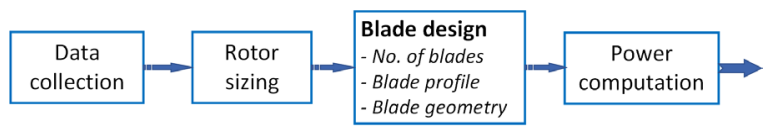

Fig. 1. Design procedure of rotary blade of wind turbines

The weather data were collected from selected local cites: Abomsa, Metehara and Ziyay, all from the eastern part of the Oromia regional state (Ethiopia). The next step is developing new designs and configurations of the rotor blades (rotor blade sizing) that can efficiently transform the energy in the wind to direct mechanical energy to drive water pumps. Fig. 2 describes the design steps that must be taken to determine the optimum rotary size of windmills to be used at those particular sites and for a particular purpose.

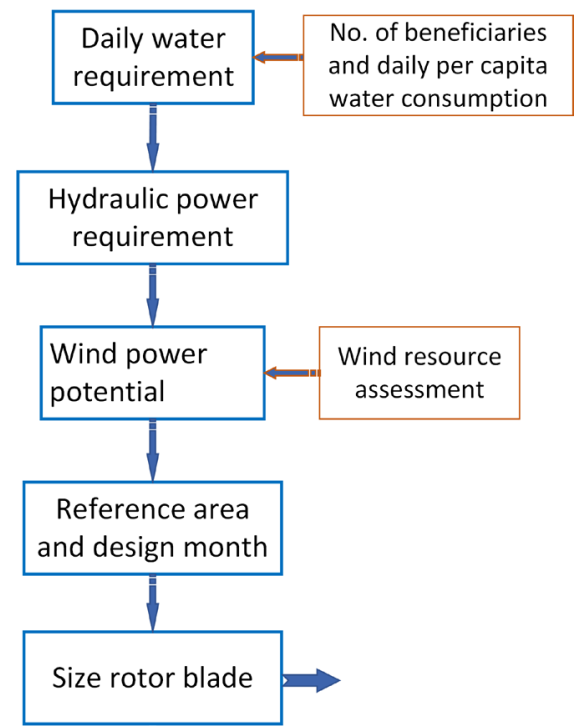

Fig. 2. Illustration of the design steps for sizing of windmill rotor for water-pumping system

Daily water requirement $\left(Q_{D}\right)$ depends on the total number of beneficiaries $\left(N_{B}\right)$ of the site and the daily water consumptions per capita $\left(q_{p p}\right)$, expressed as Eq. (1).

$$
Q_{D}=N_{B} \cdot q_{p p} .
$$

Hydraulic power requirement $\left(P_{\text {hyd }}\right)$ parameter is a function of the daily water requirement $\left(Q_{D}\right)$ and total pumping head $(H)$ as given by Eq. (2) [14] to [16], where the total pumping head includes the static water head $\left(H_{S t}\right)$ and friction losses $\left(H_{f r}\right)$, considering head losses in the pipe, velocity head losses, and other minor losses.

$$
P_{h y d}=0.113452 \cdot Q_{D} \cdot H,
$$

where $H=H_{S t}+H_{f r}$. The availability of wind power potential on a monthly basis is essential to evaluate as given in Eq. (3) [14] to [18].

$$
P_{\text {wind }}=\frac{1}{2} \rho_{\text {air }} \cdot V^{3} \text {. }
$$

Reference area $\left(A_{r}\right)$ is related to the rotor area needed to capture sufficient power from the wind as given in Eq. (4) [14] to [18].

$$
A_{r}=\frac{P_{h y d}}{P_{\text {wind }}} .
$$




\subsection{Blade Design Procedures}

After the rotary blade size of horizontal axis windmills was determined, the following steps were considered in rotary blade design.

a. Determining the minimum $C_{d} / C_{l}$ ratio: This is important to determine the value of design lift and angle of attack corresponding to a minimum value of $C_{d} / C_{l}$ ratio.

b. Determining design lift coefficient and design angle of attack $\left(\alpha_{d}\right)$ : From airfoil data corresponding to minimum $C_{d} / C_{l}$ ratio, the value of lift coefficient and angle of attack are found.

c. Choosing design tip speed ratio $(\lambda)$ and the number of blades $(B)$ : These parameters can be chosen from tip speed ratio (TSR) vs the number of blade table depending on the form of operation.

d. Determining geometries of optimum blades: When rotor blade size is determined, then it is divided into 10 to 20 equal segments or elements; for each unit element, the blade geometries such as local tip speed ratio $\lambda\left(r_{i}\right)$, relative wind angle $\psi\left(r_{i}\right)$, chord distribution $c\left(r_{i}\right)$, pitch angle $\theta\left(r_{i}\right)$, twist angle $\phi\left(r_{i}\right)$, and local solidity $\sigma\left(r_{i}\right)$ can be computed as shown in Fig. 3.

e. Linearization of the twist angle and blade chord length: Using the optimum blade shapes as a guide, a blade shape that promises to be a good approximation is selected. Since the chords as well as the blade twist vary in a non-linear manner along the blade, it is possible to linearize the chords and the twist angles using Eq. (5).

$$
\begin{aligned}
& c\left(r_{i}\right)=a_{1} r_{i}+a_{2}, \\
& \phi\left(r_{i}\right)=a_{3}\left(R-r_{i}\right),
\end{aligned}
$$

where $a_{1}, a_{2}$ and $a_{3}$ are constant coefficients obtained from the chosen chord distributions and twist angles.

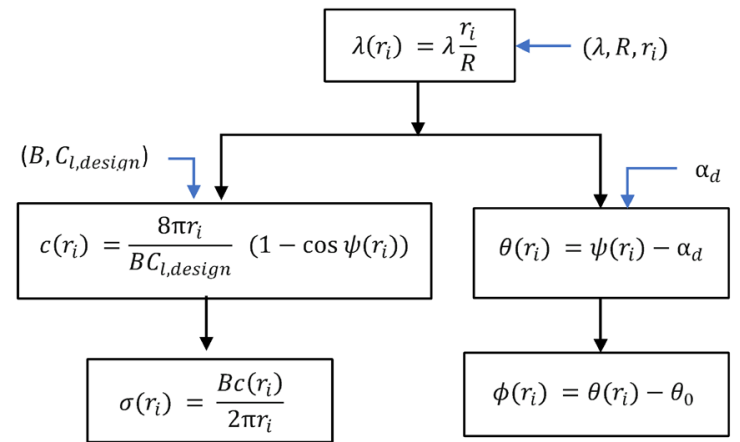

Fig. 3. Computation procedures to determine blade geometries

\subsection{Rotor Blade Performance}

After the chords and twist angles are linearized, the geometry of the rotary blade has a practical shape. The performance study of the designed rotor blade is conducted by using BEM theory [19]. Obtaining axial $a\left(r_{i}\right)_{j}$, and angular induction factors $a\left(r_{i}\right)_{j}$ of the designed blade is the base of rotor blade performances. It is possible to determine the inflow angle using the axial and angular induction factors, as follows (Eq. (6)).

$$
\psi\left(r_{i}\right)=\tan ^{-1}\left(\frac{1-a\left(r_{i}\right)_{j}}{\left(1+a\left(r_{i}\right)_{j}\right)} \frac{1}{\lambda\left(r_{i}\right)}\right) .
$$

To describe the lifting power reduction by airflow around the blade tip, the tip loss correction factor $F\left(r_{i}\right)$ for each $i^{\text {th }}$ section is calculated based on Prandtl's method [20]:

$$
F\left(r_{i}\right)=\left(\frac{2}{\pi}\right) \cos ^{-1}\left[e^{-\left(\frac{\frac{B}{2}\left(1-\frac{r_{i}}{R}\right)}{\frac{r_{i}}{R} \sin \psi\left(r_{i}\right)}\right)}\right] .
$$

The axial and tangential induction factors for each sectional $i^{\text {th }}$ element at iteration $j^{\text {th }}$ are then calculated using Eq. (8). If the axial induction factor is greater than 0.4, the Froude momentum principle is no longer accurate. Thus, Bangga [21] suggested correction of the axial induction factor, if $a\left(r_{i}\right)_{j}>a_{c}$, using Eq. (9).

$$
\begin{aligned}
a\left(r_{i}\right)_{j}= & \left(\frac{4 F\left(r_{i}\right) \sin ^{2} \psi\left(r_{i}\right)}{\sigma_{r, i}\left(C_{l, i} \cos \psi\left(r_{i}\right)+C_{d, i} \sin \psi\left(r_{i}\right)\right)}+1\right)^{-1}, \\
\dot{a}\left(r_{i}\right)_{j}= & \left(\frac{4 F\left(r_{i}\right) \cos \psi\left(r_{i}\right) \sin \psi\left(r_{i}\right)}{\sigma\left(r_{i}\right)\left(C_{l, i} \sin \psi\left(r_{i}\right)-C_{d, i} \cos \psi\left(r_{i}\right)\right)}-1\right)^{-1}, \\
a\left(r_{i}\right)_{j}= & \frac{1}{2}\left\{2+\mathrm{Z}\left(r_{i}\right)-\right. \\
& \left.\sqrt{\left(\mathrm{Z}\left(r_{i}\right)\left(1-2 a_{c}\right)+2\right)^{2}+4\left(\mathrm{Z}\left(r_{i}\right) a_{c}^{2}-1\right)}\right\},
\end{aligned}
$$

where $a_{c}$ is commonly about 0.2 and $Z\left(r_{i}\right)$ is defined as:

$$
Z\left(r_{i}\right)=\frac{4 F\left(r_{i}\right) \sin ^{2} \psi\left(r_{i}\right)}{\sigma\left(r_{i}\right)\left(C_{l, i} \cos \psi\left(r_{i}\right)+C_{d, i} \sin \psi\left(r_{i}\right)\right)} .
$$

Finally, the local thrust coefficient $C_{T}\left(r_{i}\right)$ and power coefficient $C_{P}\left(r_{i}\right)$ can be computed from the following relations. 


$$
\begin{aligned}
C_{T}\left(r_{i}\right)= & \sigma\left(r_{i}\right)\left(1-a\left(r_{i}\right)_{j}\right)^{2} \\
& \frac{\left(C_{l, i} \cos \psi\left(r_{i}\right)+C_{d, i} \sin \psi\left(r_{i}\right)\right)}{F\left(r_{i}\right) \sin ^{2} \psi\left(r_{i}\right)}, \\
C_{P}\left(r_{i}\right)= & \frac{8}{\lambda^{2}} F\left(r_{i}\right) \lambda^{3}\left(r_{i}\right) \dot{a}\left(r_{i}\right)_{j} \\
& \left(1-a\left(r_{i}\right)_{j}\right)\left(1-\frac{C_{d}}{C_{l}}\right) \cot \psi\left(r_{i}\right) .
\end{aligned}
$$

\section{ANALYSIS OF RESULTS}

The rotary blades have been designed according to data collected by NMA of Ethiopia from three selected sites (Abomsa, Metehara, and Ziway, Ethiopia). The data was collected for one year (October 2018 to September 2019) at $10 \mathrm{~m}$ height. Table 1 shows important data determined from the three selected sites, and total water demand and pumping required can be calculated by estimating the daily water consumption per capita to be $201 /$ person in Ethiopia [14] and [15]. The monthly mean wind speeds were extrapolated at $20 \mathrm{~m}$ heights (hub heights), and monthly specific wind power potentials for the three selected sites were evaluated (Table 2).

Table 1. Important parameters for three selected sites

\begin{tabular}{lccc}
\hline Parameters & Abomsa & Metehara & Ziway \\
\hline No. of beneficiaries [-] & 4086 & 4191 & 3867 \\
\hline Total demand [l] & 81720 & 83820 & 77340 \\
\hline Pumping required [m/day] & 81.72 & 83.82 & 77.34 \\
\hline Total head [m] & 87 & 79 & 74 \\
\hline Tip speed ratio, $(\lambda)[-]$ & 3 & 3.5 & 4 \\
\hline Number of blades, $(B)[-]$ & 3 & 3 & 3 \\
\hline
\end{tabular}

\begin{tabular}{|c|c|c|c|c|c|c|c|c|c|c|}
\hline \multirow[b]{2}{*}{ Year } & \multirow[b]{2}{*}{ Month } & \multicolumn{3}{|c|}{ Abomsa } & \multicolumn{3}{|c|}{ Metehara } & \multicolumn{3}{|c|}{ Ziway } \\
\hline & & $\begin{array}{c}V_{m} \text { at } 10 \\
{[\mathrm{~m} / \mathrm{s}]}\end{array}$ & $\begin{array}{c}V_{m} \text { at } 20 \\
{[\mathrm{~m} / \mathrm{s}]}\end{array}$ & $\begin{array}{c}P_{\text {wind }} \\
{[\mathrm{W}]}\end{array}$ & $\begin{array}{c}V_{m} \text { at } 10 \\
{[\mathrm{~m} / \mathrm{s}]}\end{array}$ & $\begin{array}{c}V_{m} \text { at } 20 \\
{[\mathrm{~m} / \mathrm{s}]}\end{array}$ & $\begin{array}{c}P_{\text {wind }} \\
{[\mathrm{W}]}\end{array}$ & $\begin{array}{c}V_{m} \text { at } 10 \\
{[\mathrm{~m} / \mathrm{s}]}\end{array}$ & $\begin{array}{c}V_{m} \text { at } 20 \\
{[\mathrm{~m} / \mathrm{s}]}\end{array}$ & $\begin{array}{c}P_{\text {wind }} \\
{[\mathrm{W}]}\end{array}$ \\
\hline \multirow{3}{*}{2018} & Oct & 2.82 & 3.42 & 24.59 & 2.93 & 3.56 & 27.58 & 3.82 & 4.64 & 61.12 \\
\hline & Nov & 2.81 & 3.41 & 24.33 & 2.72 & 3.30 & 22.06 & 3.92 & 4.76 & 66.04 \\
\hline & Dec & 2.99 & 3.63 & 29.31 & 2.63 & 3.19 & 19.95 & 3.56 & 4.32 & 49.47 \\
\hline \multirow{9}{*}{2019} & Jan & 3.82 & 4.64 & 61.12 & 2.63 & 3.19 & 19.95 & 3.67 & 4.46 & 54.20 \\
\hline & Feb & 3.63 & 4.41 & 52.44 & 2.92 & 3.55 & 27.30 & 3.05 & 3.70 & 31.11 \\
\hline & Mar & 3.27 & 3.97 & 38.34 & 2.53 & 3.07 & 17.76 & 2.91 & 3.53 & 27.02 \\
\hline & Apr & 2.33 & 2.83 & 13.87 & 2.65 & 3.22 & 20.40 & 2.66 & 3.23 & 20.64 \\
\hline & May & 2.76 & 3.35 & 23.05 & 2.75 & 3.34 & 22.80 & 3.01 & 3.65 & 29.90 \\
\hline & Jun & 2.58 & 3.13 & 18.83 & 3.39 & 4.12 & 42.71 & 4.14 & 5.03 & 77.80 \\
\hline & July & 2.42 & 2.94 & 15.54 & 3.36 & 4.08 & 41.59 & 3.20 & 3.89 & 35.93 \\
\hline & Aug & 2.01 & 2.44 & 8.90 & 3.23 & 3.92 & 36.95 & 3.64 & 4.42 & 52.88 \\
\hline & Sept & 2.16 & 2.62 & 11.05 & 2.75 & 3.34 & 22.80 & 2.72 & 3.30 & 22.06 \\
\hline
\end{tabular}

Based on the number of beneficiaries and total water demands, hydraulic power can be determined,

\begin{tabular}{|c|c|c|c|c|c|c|c|c|c|c|}
\hline \multirow{2}{*}{ Year } & \multirow{2}{*}{ Month } & \multicolumn{3}{|c|}{ Abomsa } & \multicolumn{3}{|c|}{ Metehara } & \multicolumn{3}{|c|}{ Ziway } \\
\hline & & $P_{\text {hyd }}$ & $A_{r}$ & $D_{r}$ & $P_{\text {hyd }}$ & $A_{r}$ & $D_{r}$ & $P_{\text {hyd }}$ & $A_{r}$ & $D_{r}$ \\
\hline \multirow{3}{*}{2018} & Oct & 806.3 & 32.8 & 6.5 & 750.9 & 27.2 & 5.9 & 649.1 & 10.6 & 3.7 \\
\hline & Nov & 806.3 & 33.1 & 6.5 & 750.9 & 34.0 & 6.6 & 649.1 & 9.8 & 3.5 \\
\hline & Dec & 806.3 & 27.5 & 5.9 & 750.9 & 37.7 & 6.9 & 649.1 & 13.1 & 4.1 \\
\hline \multirow{9}{*}{2019} & Jan & 806.3 & 13.2 & 4.1 & 750.9 & 37.7 & 6.9 & 649.1 & 12.0 & 3.9 \\
\hline & Feb & 806.3 & 15.4 & 4.4 & 750.9 & 27.5 & 5.9 & 649.1 & 20.9 & 5.2 \\
\hline & Mar & 806.3 & 21.0 & 5.2 & 750.9 & 42.3 & 7.3 & 649.1 & 24.0 & 5.5 \\
\hline & Apr & 806.3 & 58.1 & 8.6 & 750.9 & 36.8 & 6.9 & 649.1 & 31.5 & 6.3 \\
\hline & May & 806.3 & 35.0 & 6.7 & 750.9 & 32.9 & 6.5 & 649.1 & 21.7 & 5.3 \\
\hline & Jun & 806.3 & 42.8 & 7.4 & 750.9 & 17.6 & 4.7 & 649.1 & 8.3 & 3.3 \\
\hline & July & 806.3 & 51.9 & 8.1 & 750.9 & 18.1 & 4.8 & 649.1 & 18.1 & 4.8 \\
\hline & Aug & 806.3 & 90.6 & 10.7 & 750.9 & 20.3 & 5.1 & 649.1 & 12.3 & 4.0 \\
\hline & Sept & 806.3 & 73.0 & 9.6 & 750.9 & 32.9 & 6.5 & 649.1 & 29.4 & 6.1 \\
\hline
\end{tabular}

Table 2. Available mean wind speeds and specific wind power for three selected sites

Table 3. Hydraulic power, reference area and rotor diameter for three selected sites 


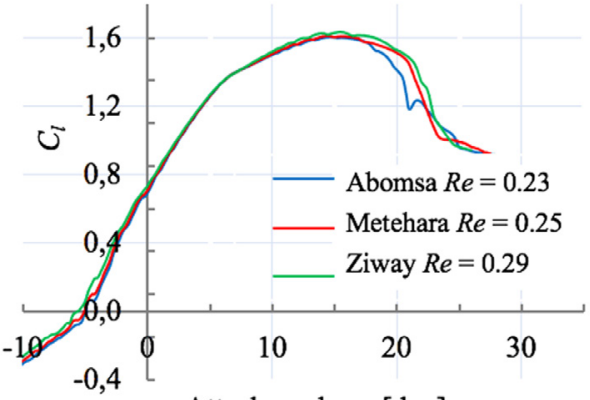

a)

Attack angle, $\alpha[\mathrm{deg}]$

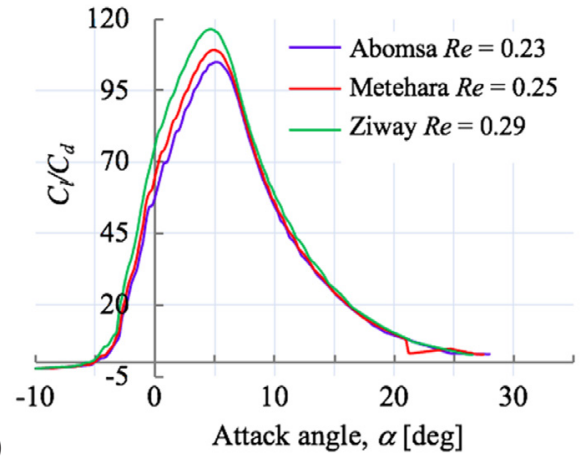

Fig. 4. Lift coefficient a) $C_{l}$ and b) $C_{l} / C_{d}$ of SG6043 with Reynolds numbers of three sites

which is constant through the year, the reference area and rotor diameter for the three sites were calculated and summarized in Table 3. The rotor size is chosen on the basis of "design month", which is the month in which the water demand is highest in relation to the wind power resources, i.e., the month when the system will be most heavily loaded [14] and [16].

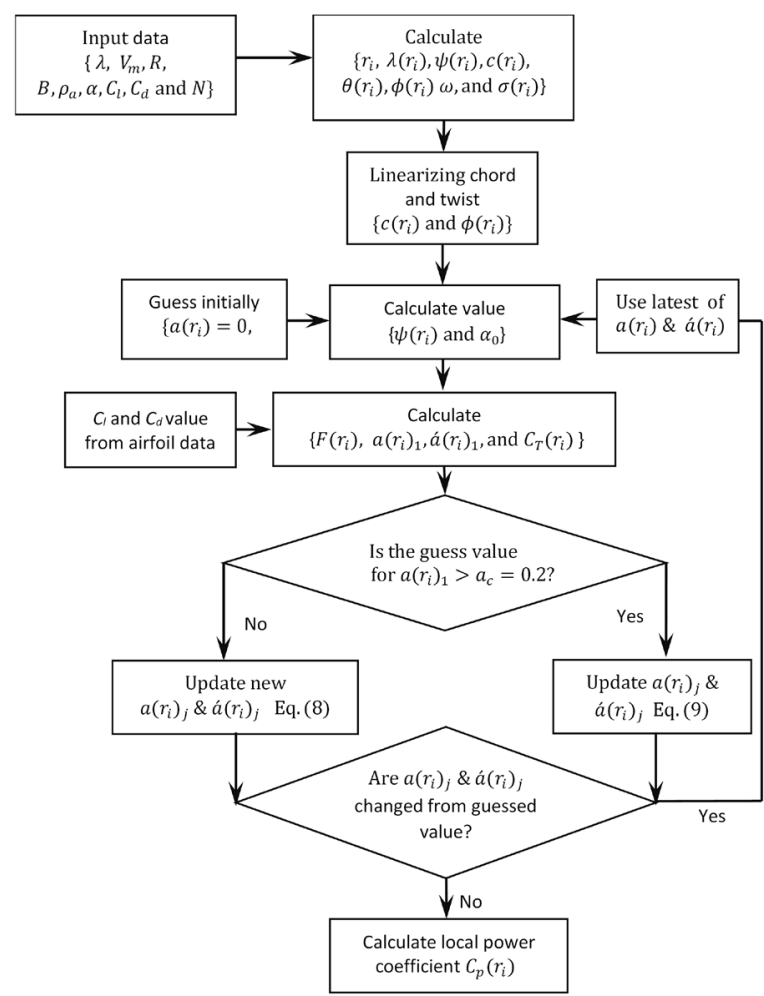

Fig. 5. Flow diagram of performing rotor blades design

Therefore, according to the data given in Table 3, August, March and April are the design months for Abomsa, Metehara and Ziway, respectively.

For three rotor blade design, Giguere and Selig [11] and Osei [12] recommended airfoil type SG6043 for low Reynolds numbers because this type of airfoil operates in regional low wind speed. The designed $C_{l}$

Table 4. Geometric properties of optimum and linearized rotor blades for Abomsa site

\begin{tabular}{|c|c|c|c|c|c|c|c|c|}
\hline \multirow{2}{*}{$r_{i} / R$} & \multicolumn{4}{|c|}{ Optimal blade } & \multicolumn{4}{|c|}{ Linearized blade } \\
\hline & $\psi\left(r_{i}\right)$ & $\theta\left(r_{i}\right)$ & $\phi\left(r_{i}\right)$ & $c\left(r_{i}\right)$ & $\psi\left(r_{i}\right)$ & $\theta\left(r_{i}\right)$ & $\phi\left(r_{i}\right)$ & $c\left(r_{i}\right)$ \\
\hline 0.07 & 52.46 & 47.46 & 40.17 & 0.39 & 24.83 & 19.83 & 20.79 & 0.77 \\
\hline 0.13 & 45.47 & 40.47 & 33.18 & 0.59 & 23.34 & 18.34 & 19.30 & 0.73 \\
\hline 0.20 & 39.36 & 34.36 & 27.07 & 0.68 & 21.86 & 16.86 & 17.82 & 0.70 \\
\hline 0.27 & 34.23 & 29.23 & 21.94 & 0.69 & 20.37 & 15.37 & 16.33 & 0.67 \\
\hline 0.33 & 30.00 & 25.00 & 17.71 & 0.66 & 18.89 & 13.89 & 14.85 & 0.64 \\
\hline 0.40 & 26.54 & 21.54 & 14.25 & 0.63 & 17.40 & 12.40 & 13.36 & 0.61 \\
\hline 0.47 & 23.69 & 18.69 & 11.40 & 0.59 & 15.92 & 10.92 & 11.88 & 0.58 \\
\hline 0.53 & 21.34 & 16.34 & 9.05 & 0.54 & 14.43 & 9.43 & 10.39 & 0.54 \\
\hline 0.60 & 19.37 & 14.37 & 7.08 & 0.51 & 12.95 & 7.95 & 8.91 & 0.51 \\
\hline 0.67 & 17.71 & 12.71 & 5.42 & 0.47 & 11.46 & 6.46 & 7.42 & 0.48 \\
\hline 0.73 & 16.30 & 11.30 & 4.01 & 0.44 & 9.98 & 4.98 & 5.94 & 0.45 \\
\hline 0.80 & 15.08 & 10.08 & 2.79 & 0.41 & 8.49 & 3.49 & 4.45 & 0.42 \\
\hline 0.87 & 14.03 & 9.03 & 1.74 & 0.38 & 7.01 & 2.01 & 2.97 & 0.39 \\
\hline 0.93 & 13.10 & 8.10 & 0.81 & 0.36 & 5.52 & 0.52 & 1.48 & 0.35 \\
\hline 1.00 & 12.29 & 7.29 & 0.00 & 0.34 & 4.04 & -0.96 & 0.00 & 0.32 \\
\hline
\end{tabular}



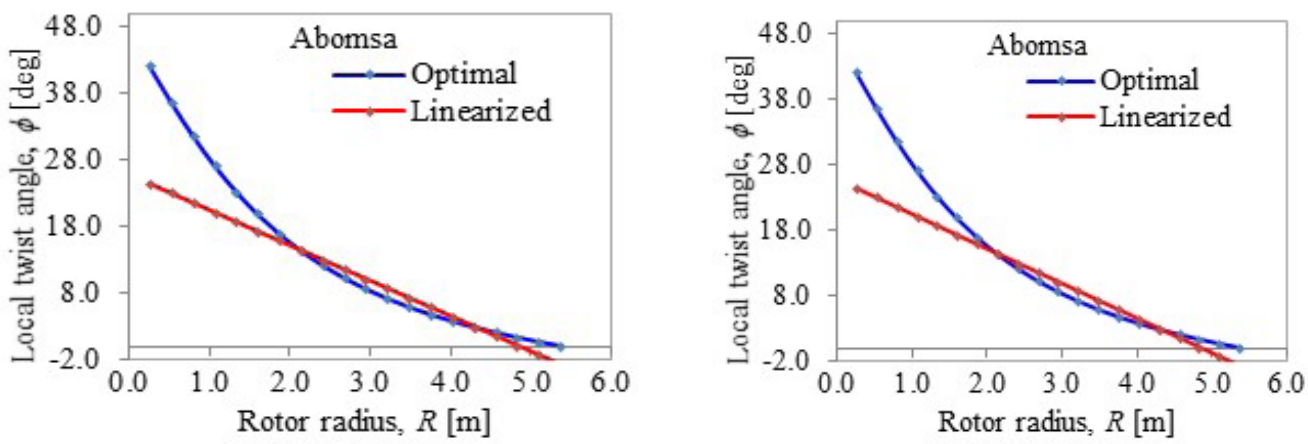

a)
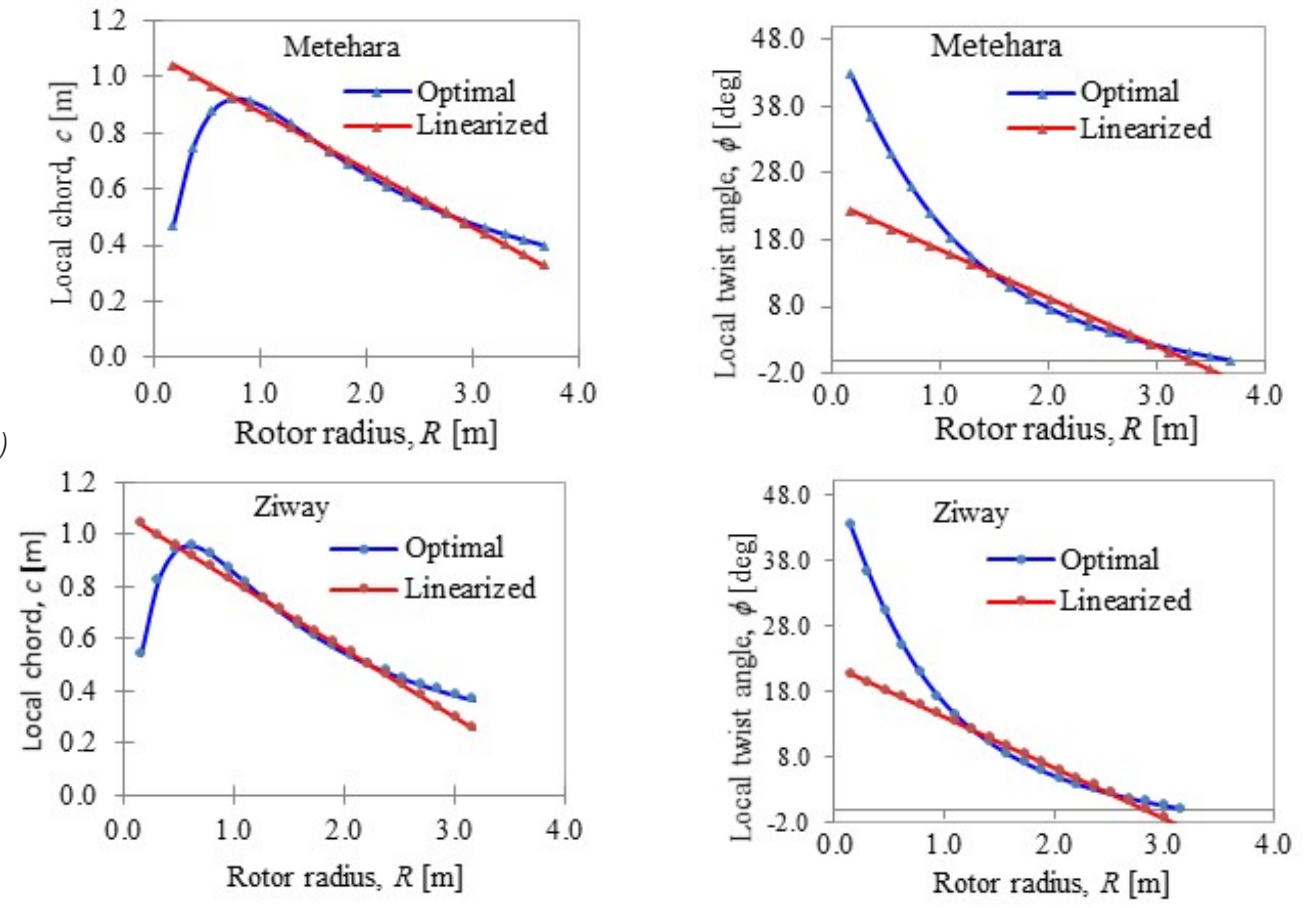

Fig. 6. Local chord and twist angle comparison of optimal and linearized blades for three sites, a) Abomsa, b) Metehara, and c) Ziway

Table 5. Geometric properties of optimum and linearized rotor blade for Metehara site

\begin{tabular}{|c|c|c|c|c|c|c|c|c|}
\hline \multirow[b]{2}{*}{$r_{i} / R$} & \multicolumn{4}{|c|}{ Optimal blade } & \multicolumn{4}{|c|}{ Linearized blade } \\
\hline & $\psi\left(r_{i}\right)$ & $\theta\left(r_{i}\right)$ & $\phi\left(r_{i}\right)$ & $c\left(r_{i}\right)$ & $\psi\left(r_{i}\right)$ & $\theta\left(r_{i}\right)$ & $\phi\left(r_{i}\right)$ & $c\left(r_{i}\right)$ \\
\hline 0.07 & 51.24 & 46.24 & 40.61 & 0.43 & 23.04 & 18.04 & 18.98 & 0.73 \\
\hline 0.13 & 43.32 & 38.32 & 32.69 & 0.63 & 21.68 & 16.68 & 17.62 & 0.70 \\
\hline 0.20 & 36.67 & 31.67 & 26.04 & 0.69 & 20.33 & 15.33 & 16.27 & 0.66 \\
\hline 0.27 & 31.32 & 26.32 & 20.69 & 0.67 & 18.97 & 13.97 & 14.91 & 0.63 \\
\hline 0.33 & 27.07 & 22.07 & 16.44 & 0.63 & 17.62 & 12.62 & 13.56 & 0.60 \\
\hline 0.40 & 23.69 & 18.69 & 13.06 & 0.59 & 16.26 & 11.26 & 12.20 & 0.57 \\
\hline 0.47 & 20.98 & 15.98 & 10.35 & 0.54 & 14.91 & 9.91 & 10.85 & 0.54 \\
\hline 0.53 & 18.79 & 13.79 & 8.16 & 0.49 & 13.55 & 8.55 & 9.49 & 0.50 \\
\hline 0.60 & 16.98 & 11.98 & 6.35 & 0.45 & 12.19 & 7.19 & 8.13 & 0.47 \\
\hline 0.67 & 15.47 & 10.47 & 4.84 & 0.42 & 10.84 & 5.84 & 6.78 & 0.44 \\
\hline 0.73 & 14.19 & 9.19 & 3.56 & 0.39 & 9.48 & 4.48 & 5.42 & 0.41 \\
\hline 0.80 & 13.10 & 8.10 & 2.47 & 0.36 & 8.13 & 3.13 & 4.07 & 0.38 \\
\hline 0.87 & 12.16 & 7.16 & 1.53 & 0.34 & 6.77 & 1.77 & 2.71 & 0.35 \\
\hline 0.93 & 11.35 & 6.35 & 0.72 & 0.32 & 5.42 & 0.42 & 1.36 & 0.31 \\
\hline 1.00 & 10.63 & 5.63 & 0.00 & 0.30 & 4.06 & -0.94 & 0.00 & 0.28 \\
\hline
\end{tabular}




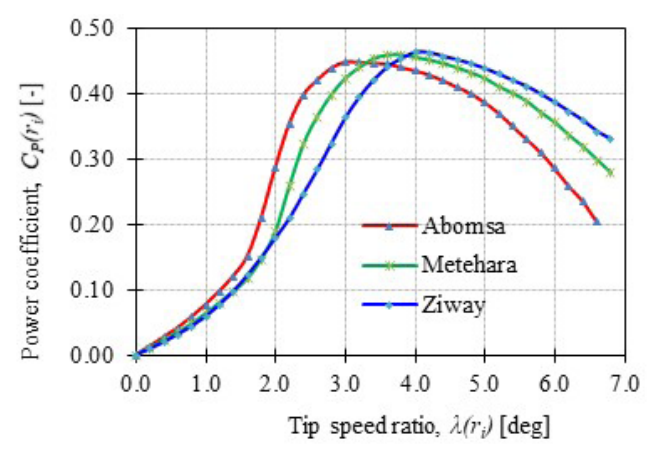

Fig. 7. The vs. of rotor performed blades for three selected sites

and $C_{l} / C_{d}$ graphs characteristics of SG6043 with Re of $0.23 \times 10^{6}, 0.25 \times 10^{6}$ and $0.29 \times 10^{6}$ are evaluated, as illustrated in Fig. 4, using QBlade, for Abomsa, Metehara, and Ziway, respectively. Fig. 5 shows the general flow diagram for determining blade geometries and performing the designed blades by iterating axial and tangential induction factors.

The blade geometries are determined with the number of segments or elements $(N)$ equal to 15 .
The local chord distributions, geometries set angles, and solidities of optimal and linearized blades for the three selected sites are determined and summarized in Tables 4, 5 and 6. The comparison of blade chord distributions and sectional angles of twist for optimal and linearized blades for the three selected sites are illustrated in Fig. 6.

Based on the BEM flow diagram of iteration in Fig. 5, each local axial and tangential induction factors have converged after many iterations by MATALB coding and the coefficients of performance are illustrated as shown in Fig. 7 for these three local sites. The geometry profiles (shape) of designed and optimized rotor blades are modelled by QBlade software, and the resulting blades are shown in Fig. 8. As can be observed from this figure, the maximum coefficient of performance values of $C_{P}\left(r_{i}\right)$ are 0.448 , 0.459 and 0.463 at the maximum tip speed ratio of $\lambda\left(r_{i}\right) 3.0,3.5$ and 4.0 for the three sites Abomsa, Metehara and Ziway respectively. The geometry shape of optimal, linearized and optimized designed blades modelled by QBlade software and the resulting blades are shown in Fig. 8.
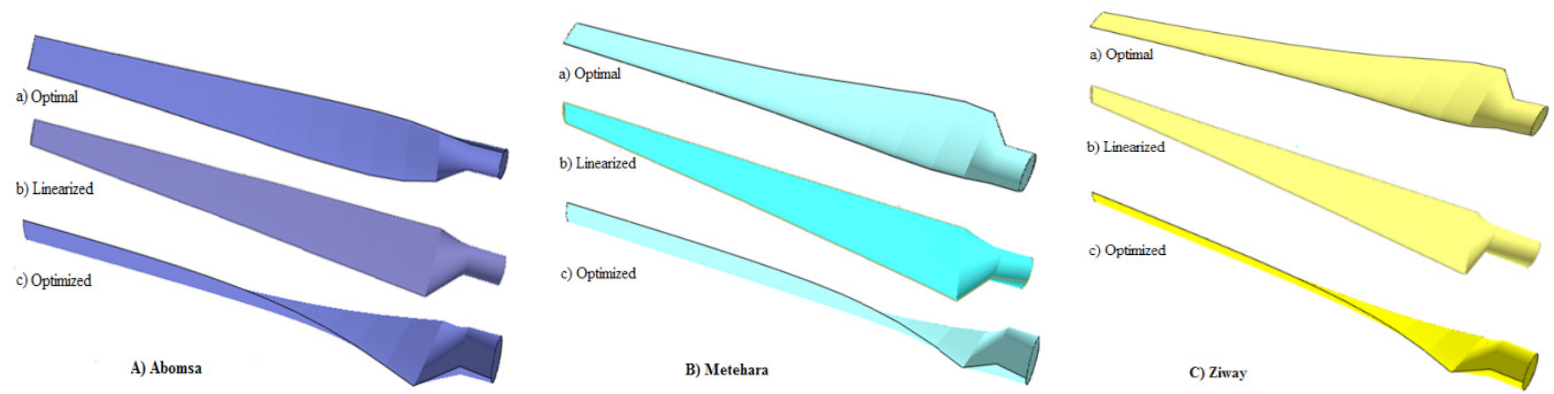

Fig. 8. Geometry shape of optimal, linearized and optimized blades modelled by QBlade for A) Abomsa, B) Metehara and C) Ziway sites.

Table 6. Geometric properties of Optimum and linearized rotor blades for Ziway site

\begin{tabular}{|c|c|c|c|c|c|c|c|c|}
\hline \multirow{2}{*}{$r_{i} / R$} & \multicolumn{4}{|c|}{ Optimal blade } & \multicolumn{4}{|c|}{ Linearized blade } \\
\hline & $\psi\left(r_{i}\right)$ & $\theta\left(r_{i}\right)$ & $\phi\left(r_{i}\right)$ & $c\left(r_{i}\right)$ & $\psi\left(r_{i}\right)$ & $\theta\left(r_{i}\right)$ & $\phi\left(r_{i}\right)$ & $c\left(r_{i}\right)$ \\
\hline 0.07 & 50.05 & 45.05 & 40.69 & 0.47 & 21.41 & 16.41 & 17.29 & 0.67 \\
\hline 0.13 & 41.29 & 36.29 & 31.93 & 0.66 & 20.17 & 15.17 & 16.05 & 0.64 \\
\hline 0.20 & 34.23 & 29.23 & 24.87 & 0.69 & 18.94 & 13.94 & 14.82 & 0.61 \\
\hline 0.27 & 28.77 & 23.77 & 19.41 & 0.65 & 17.70 & 12.70 & 13.58 & 0.58 \\
\hline 0.33 & 24.58 & 19.58 & 15.22 & 0.60 & 16.47 & 11.47 & 12.35 & 0.55 \\
\hline 0.40 & 21.34 & 16.34 & 11.98 & 0.54 & 15.23 & 10.23 & 11.11 & 0.52 \\
\hline 0.47 & 18.79 & 13.79 & 9.43 & 0.49 & 14.00 & 9.00 & 9.88 & 0.49 \\
\hline 0.53 & 16.74 & 11.74 & 7.38 & 0.45 & 12.76 & 7.76 & 8.64 & 0.46 \\
\hline 0.60 & 15.08 & 10.08 & 5.72 & 0.41 & 11.53 & 6.53 & 7.41 & 0.43 \\
\hline 0.67 & 13.70 & 8.70 & 4.34 & 0.38 & 10.30 & 5.30 & 6.18 & 0.39 \\
\hline 0.73 & 12.55 & 7.55 & 3.19 & 0.35 & 9.06 & 4.06 & 4.94 & 0.36 \\
\hline 0.80 & 11.57 & 6.57 & 2.21 & 0.32 & 7.83 & 2.83 & 3.71 & 0.33 \\
\hline 0.87 & 10.73 & 5.73 & 1.37 & 0.30 & 6.59 & 1.59 & 2.47 & 0.30 \\
\hline 0.93 & 10.00 & 5.00 & 0.64 & 0.28 & 5.36 & 0.36 & 1.24 & 0.27 \\
\hline 1.00 & 9.36 & 4.36 & 0.00 & 0.26 & 4.12 & -0.88 & 0.00 & 0.24 \\
\hline
\end{tabular}




\section{CONCLUSION}

In this study, the optimum rotary blade for a windpowered water pumping system for local three selected sites has been designed and analysed. From these designs, the optimal blade parameters are determined, linearized, and optimized. The geometry profiles of optimized blades are modelled using QBlade software for the three local selected sites. The key results of the design and analysis work show that the maximum coefficient of performance values $C_{p}\left(r_{i}\right)$ are $0.4512,0.4587$, and 0.4627 at the maximum tip speed ratio $\lambda\left(r_{i}\right)$ values of $3.0,3.5$ and 4.0 for the three sites Abomsa, Metehara, and Ziway, respectively. Furthermore, the average wind speeds at a height of $20 \mathrm{~m}$ are $3.50 \mathrm{~m} / \mathrm{s}, 3.60 \mathrm{~m} / \mathrm{s}$ and $4.60 \mathrm{~m} / \mathrm{s}$, respectively.

This article is part of a $\mathrm{PhD}$ research whose further work will focus on developing the design model of the blade with the obtained design specification and building a prototype wind turbine to test at the three locations.

\section{NOMENCLATURE}

\begin{tabular}{|c|c|}
\hline$a\left(r_{i}\right)$ & Axial induction factor, [-] \\
\hline$\dot{a}\left(r_{i}\right)$ & Angular induction factor, [-] \\
\hline$a_{1}, a_{2}, a$ & Constant coefficient, [-] \\
\hline$A_{r}$ & Reference area, $\left[\mathrm{m}^{2}\right]$ \\
\hline$c\left(r_{i}\right)$ & Chord distribution, $[-]$ \\
\hline$C_{d, i}$ & Local drag coefficient, [-] \\
\hline$C_{d}$ & Drag coefficient, [-] \\
\hline$C_{l, i}$ & Local lift coefficient, [-] \\
\hline$C_{l}$ & Lift coefficient, [-] \\
\hline$C_{P}\left(r_{i}\right)$ & Local power coefficient, [-] \\
\hline$C_{T}\left(r_{i}\right)$ & Local thrust coefficient, [-] \\
\hline$F\left(r_{i}\right)$ & Blade tip loss factor, [-] \\
\hline$H$ & Total pumping head, $[\mathrm{m}]$ \\
\hline$H_{f r}$ & Friction losses, $[\mathrm{m}]$ \\
\hline$H_{s t}$ & Static water head, $[\mathrm{m}]$ \\
\hline$N_{B}$ & Total number of beneficiaries [-] \\
\hline$P_{\text {hyd }}$ & Hydraulic power requirement [W] \\
\hline$P_{\text {wind }}$ & Wind power potential $\left[\mathrm{W} / \mathrm{m}^{2}\right]$ \\
\hline$Q_{D}$ & Daily water requirement, $\left[\mathrm{m}^{3} /\right.$ day $]$ \\
\hline$q_{p p}$ & Water consumption per capita, [1/day] \\
\hline$R$ & Rotor blade radius, $[\mathrm{m}]$ \\
\hline$r_{i}$ & Local radius, $[\mathrm{m}]$ \\
\hline$V_{m}$ & Wind velocity, $[\mathrm{m} / \mathrm{s}]$ \\
\hline$\alpha_{d}$ & Design attack angle, [deg] \\
\hline$\theta\left(r_{i}\right)$ & Pitch angle, $[\mathrm{deg}]$ \\
\hline$\lambda\left(r_{i}\right)$ & Local tip speed ratio, $[-]$ \\
\hline$\lambda$ & Tip speed ratio, [-] \\
\hline & Air density, $\left[\mathrm{kg} / \mathrm{m}^{3}\right]$ \\
\hline$\sigma\left(r_{i}\right)$ & Local solidity, $\left[\mathrm{m}^{-1}\right]$ \\
\hline
\end{tabular}

$\phi\left(r_{i}\right) \quad$ Twist angle, [deg]

$\psi\left(r_{i}\right) \quad$ Relative wind angle, [deg]

\section{REFERENCES}

[1] Ahamed, E.Z., Gowtham, A.R. (2015). Aero-design analysis for modified Darrieus based-straight bladed VAWT systems. International Journal of Recent Technology and Engineering, vol. 4, no. 5, p. 510-514, Dol:10.15623/ijret.2015.0405095.

[2] Supreeth, R., Arokkiaswamy, A, Nagarjun, J.R., Prajwal, H.P, Sudhanva, M. (2019). Geometrical design of a rotor blade for a small-scale horizontal axis wind turbine. International Journal of Recent Technology and Engineering, vol. 8, no. 3, p. 33903400.

[3] Prasad, S.S., Virupaxi, A. (2012). Optimized design of rotor blade for a wind pump. International Journal of Renewable Energy Research, vol. 2, no. 4, P. 746-749.

[4] Lopez-Lopez, A., Robles-Ocampo, J.B., Sevilla-Camacho, P.Y., Lastres-Danguillecourt, O., Muniz, J., Perez-Sariñana, B.Y., de la Cruz, S. (2020). Dynamic instability of a wind turbine blade due to large deflections: An experimental validation. Strojniški vestnik - Journal of Mechanical Engineering, vol. 66, no. 9, p. 523- 533, D0l:10.5545/sv-jme.2020.6678.

[5] Lee, S.-L., Shin, S.J. (2020). Wind turbine blade optimal design considering multi-parameters and response surface method. Energies, vol. 13, no. 7, art. ID 1639, D0l:10.3390/ en13071639.

[6] Shubham, R., Shubham, S., Rohan, S., Navjyot, S., Chaudhary, M.K. (2017). Simulation of micro wind turbine blade in QBlade. International Journal for Research in Applied Science and Engineering Technology, vol. 5, no. IV, p. 256-262.

[7] Chan, Z.M. (2019). Design calculation of 1200W horizontal axis wind turbine blade for rural applications. International Journal of Trend in Scientific Research and Development, vol. 3, no. 5, p. 500-507.

[8] Deepak, J.N., Chandan, R., Doddanna, K. (2017). Design \& structural analysis of a small wind turbine blade for operation at low wind speed. International Research Journal of Engineering and Technology, vol. 4, no. 11, p. 2188-2191.

[9] Muhsen, H. Al-Kouz, W., Khan, W. (2020). Small wind turbine blade design and optimization. Symmetry, vol. 12, no. 1, art. ID 18, D0I:10.3390/sym12010018.

[10] Noronha, N.P., Krishna, M. (2020). Design and analysis of micro horizontal axis wind turbine using MATLAB and QBlade. International Journal of Advanced Science and Technology, vol. 9, no. 10S, p. 8877-8885.

[11] Giguere, P., Selig, M.S. (1998). New airfoils for small horizontal, axis wind turbines. Journal of Solar Energy Engineering, vol. 120, no. 2, p. 108-114, D0I:10.1115/1.2888052.

[12] Osei, E.Y., Opoku, R., Sunnu, A.K., Adaramola, M.S. (2020). Development of high performance airfoils for application in small wind turbine power generation. Journal of Energy, vol 2020, art ID. 9710189, DOI:10.1155/2020/9710189.

[13] Mohammed, A., Lemu, H.G., Sirahbizu, B. (2020). Statistical analysis of Ethiopian wind power potential at selected sites. Proceedings of $8^{\text {th }}$ EAl International Conference on Advancements of Science and Technology, Bahir Dar. 
[14] Ronak, D.G., Pramod, K., Debarshi, S., Bhushan, K., Shubham, C. (2015). Design and development of windmill operated water pump. International Journal of Innovative Research in Science, Engineering and Technology, vol. 5, no. 1, p. 61-74.

[15] Girma, M., Molina, M., Assefa, A. (2015). Feasibility study of a wind powered water pumping system for rural Ethiopia. AIMS Energy, vol. 3, no. 4, p. 851-868, Dol:10.3934/ energy.2015.4.851.

[16] African Water Facility (AWF) (2008). Ethiopia-Utilization of solar and wind energy for rural water supply in Ethiopia. Appraisal report, Ministry of Water Resources, Addis Abeba.

[17] Sathyajith, M. (2006). Wind Energy, Fundamentals, Resource Analysis and Economics. Springer Verlag, Berlin Heidelberg, DOI:10.1007/3-540-30906-3.
[18] Ahmmed, S. (2002). Investigation and Analysis of Wind Pumping System for Irrigation in Bangladesh. Bangladesh University of Engineering and Technology, PhD Thesis, Dhaka.

[19] Yang, K. (2020). Geometry design optimization of a wind turbine blade considering effects on aerodynamic performance by linearization. Energies, vol. 13, no. 9, art. ID 2320, DOl:10.3390/en13092320.

[20] Burton, T., Sharpe, D. (2006). Wind Energy Handbook. John Wiley \& Sons Ltd., Chichester.

[21] Bangga, G. (2018). Comparison of blade element method and CFD simulations of a $10 \mathrm{MW}$ Wind Turbine. Fluids, vol. 3, no. 4, art ID 73, D0I:10.3390/fluids3040073. 